\title{
PTPRR, Cerebellum, and Motor Coordination
}

\author{
Ina Schmitt • Emmanuelle Bitoun • Mario Manto
}

Published online: 2 June 2009

(C) Springer Science + Business Media, LLC 2009

\begin{abstract}
Tyrosine phosphorylation is a powerful mechanism of modulation for proliferation, differentiation, and functioning of neurons. The protein products of the neuronal mouse gene PTPRR are physiological regulators of mitogen-activated protein kinase (MAPK) activities. $\mathrm{PTPRR}^{-/}$mice display deficits of motor coordination and balance skills. PTPRR gene orthologues are found in many vertebrates. Recent observations suggest that the human episodic ataxia 2 (EA2) and spinocerebellar ataxia types 6 (SCA6), 12 (SCA12), and 14 (SCA14) might be associated with impaired phosphorylation levels of cerebellum calcium channels and receptors. The concept that MAPK signaling is a key process in tuning synaptic plasticity in cerebellar circuits is now emerging, with numerous implications for understanding cerebellar functions and cerebellar disorders.
\end{abstract}

Keywords Cerebellum · Phosphorylation · Calcium . PTPRR · Ataxia

Signaling plays a key role in the circuitries of the central nervous system (CNS). Reversible phosphorylation of

\footnotetext{
I. Schmitt

Department of Neurology, UKB Bonn,

Bonn, Germany

E. Bitoun

MRC Functional Genomics Unit, University of Oxford, Oxford, UK

M. Manto $(\square)$

FNRS Neurologie, ULB Erasme,

808 Route de Lennik,

Brussels 1070, Belgium

e-mail: mmanto@ulb.ac.be
}

proteins is one of the mechanisms for signaling procedures. Tyrosine phosphorylation is a powerful way to modulate protein-mediated processes related to proliferation, differentiation, and functioning of neurons. Abnormal protein phosphorylation is associated with neurological disorders. In the cerebellum, autism, mental retardation, epilepsy, and ataxias have been linked to aberrant phosphorylation [1]. In the brain, the mitogen-activated protein kinase (MAPK) cascade is a major signaling pathway and as such is tightly controlled. Activation of upstream kinases and inactivation of phosphatases are involved, controlling spatial and temporal ratio of tyrosine-phosphorylated and non-phosphorylated targets. Once activated by dual phosphorylation, MAPKs phosphorylate a large range of cytosolic and nuclear substrates [2]. Some phosphatases contain a kinase interaction motif (KIM) that mediates selective binding to the MAPK common docking domain [3], ensuring retention and inactivation of the MAPK in the cytosol. Three human genes encode KIMcontaining tyrosine-specific phosphatases: PTPN5, PTPN7, and PTPRR. Protein tyrosine phosphatases (PTPs) are key players in numerous cellular processes. Mechanisms of PTP regulation include alternative mRNA splicing, modulation of steady-state levels, posttranslational modification, dimerization, and/or subcellular confinement [4].

In this issue, Hendriks et al. [5] discuss the physiological regulators of MAPK activities. The protein products of the neuronal mouse gene Ptprr (i.e., PTPBR7, PTP-SL, PTPPBSc-42, and PTPPBSc-37; [6]) are amongst these regulators. PTPRR gene orthologues are present in many vertebrates. During cerebellar maturation, PTPBR7 expression in developing Purkinje cells is replaced by PTP-SL expression in the mature Purkinje cells. The authors have generated mice that lack all four PTPRR isoforms and have found that ERK1/2 phosphorylation levels in $\mathrm{Ptprr}^{-/-}$brain tissue are increased when compared with wild-type material. 
Ptprr $^{-/}$mice display defects of fine motor coordination and abnormal balance skills in multiple tests. These findings show a role for PTPRR proteins in motor control and proper cerebellar activity, in agreement with the predominant expression of PTPRR in adult cerebellum Purkinje cells. Interestingly, the total number of Purkinje cells or their dendritic branching is unaffected and there is no histological sign of neurodegeneration.

Mutant mice that display ataxic behavior but have apparently normal cerebellar layering, Purkinje cell numbers, and dendritic spine morphology are limited, unlike the majority of ataxia mouse models displaying loss of cerebellar granule cells or Purkinje neurons. Examples include junctophilin 3 [7], carbonic anhydrase-related protein VIII (Car8) [8], and calretinin-deficient mice [9]. These mice are ataxic because of a deregulation of calcium homeostasis which impacts not only on Purkinje cell behavior but also upon other neurons of the cerebellar cortex [9]. Junctophilins contribute to the formation of junctional membrane complexes by spanning the endoplas$\mathrm{mic} /$ sarcoplasmic reticulum membrane and interacting with the plasma membrane. Car8 is a binding protein for the IP3 receptor expressed in cerebellar Purkinje neurons and plays a role in fine-tuning of the intracellular calcium level in the dendrites of Purkinje neurons. Calretinin belongs to the large family of EF-hand calcium-binding proteins and is thought to confer a general protection against the pathogenic mechanisms of neuron disease [10]. Furthermore, silencing of small-conductance calcium-activated potassium channels, regulators of firing frequency, in the CNS has proved that a purely electrical alteration is sufficient to cause cerebellar ataxia [11]. Even an anti-Ca ${ }^{2+}$ channel antibody was sufficient to inhibit voltage-gated $\mathrm{Ca}^{2+}$ channels, alter cerebellar synaptic transmission, and confer the phenotype of cerebellar ataxia [12].

The human episodic ataxia 2 (EA2), familial hemiplegic migraine 1 , and spinocerebellar ataxia 6 (SCA6), which all result from mutations in the pore-forming subunit of $\mathrm{P} / \mathrm{Q}-$ type voltage-gated calcium channels [13], can be classified as disorders of the neuronal phosphoproteome. Familial spinocerebellar ataxia types 12 (SCA12) and 14 (SCA14), caused by mutations in genes encoding the phosphatase $\mathrm{PP} 2 \mathrm{~A}$ regulatory subunit $\mathrm{PR} 55 / \mathrm{Bb}$ [14] and the kinase PKC $\gamma[15,16]$, respectively, might be associated with impaired phosphorylation levels of cerebellum calcium channels and receptors. SCA14 mutations induce a PKC $\gamma$ superkinase that phosphorylates brain glutamate receptors [17]. There is a failure to phosphorylate transient receptor potential channels, resulting in sustained $\mathrm{Ca}^{2+}$ entry [18]. In the cerebellum of Ptprr $^{-/}$mice, increased phospho-ERK1/2 immunostaining is found predominantly at the basal portions of the Purkinje cell soma, including the axon hillock region. This is the zone where inhibitory basket cell afferents regulate Purkinje cell firing via synaptic transmission. Irregularities in Purkinje cell pacemaking induce cerebellar dysfunction and consecutively ataxia [19]. Current studies demonstrate that the ERK1/2 MAPKs are physiologically relevant PTPRR substrates. The concept that MAPK signaling is a key process in tuning synaptic plasticity is emerging. The direct and indirect implications for understanding cerebellar functions and cerebellar disorders are numerous. Elucidation of the molecular mechanisms by which PTPRR deficiency generates defects in motor coordination may provide new keys to open the door not only to symptomatic therapies of cerebellar ataxias, including the so-called sporadic ataxias and the hereditary ataxias [20], but also to the unraveling of candidate genes in inherited disorders. Furthermore, our understanding of the roles of the cerebellum in motor coordination [21] will benefit from these discoveries. Because phosphorylation of key proteins mediating chromatin remodeling and gene transcription plays an important role in controlling brain development, synaptogenesis, learning, and memory [22], there is a need for deciphering the details of these elemental processes in cerebellar research, especially for innovative translational research.

\section{References}

1. Chizhikov V, Millen KJ (2003) Development and malformations of the cerebellum in mice. Mol Genet Metab 80:54-65

2. Krens SF, Spaink HP, Snaar-Jagalska BE (2006) Functions of the MAPK family in vertebrate development. FEBS Lett 580:49844990

3. Tanoue T, Nishida E (2003) Molecular recognitions in the MAP kinase cascades. Cell Signal 15:455-462

4. den Hertog J, Östman A, Böhmer F-D (2008) Protein tyrosine phosphatases: regulatory mechanisms. FEBS J 275:831-847

5. Hendriks WJA, Dilaver G, Noordman YE, Kremer B, Fransen JAM (2009) PTPRR Protein tyrosine phosphatase isoforms and locomotion of vesicles and mice. Cerebellum doi:10.1007/s12311008-0088-y

6. Chirivi RGS, Dilaver G, van de Vorstenbosch R, Wanschers B, Schepens J, Croes H, Fransen J, Hendriks W (2004) Characterization of multiple transcripts and isoforms derived from the mouse protein tyrosine phosphatase gene Ptprr. Genes Cells 9:919-933

7. Nishi M, Hashimoto K, Kuriyama K, Komazaki S, Kano M, Shibata S, Takeshima H (2002) Motor discoordination in mutant mice lacking junctophilin type 3. Biochem Biophys Res Commun 292:318-324

8. Jiao Y, Yan J, Zhao Y, Donahue LR, Beamer WG, Li X, Roe BA, Ledoux MS, Gu W (2005) Carbonic anhydrase-related protein VIII deficiency is associated with a distinctive lifelong gait disorder in waddles mice. Genetics 171:1239-1246

9. Cheron G, Gall D, Servais L, Dan B, Maex R, Schiffmann SN (2004) Inactivation of calcium-binding protein genes induces $160 \mathrm{~Hz}$ oscillations in the cerebellar cortex of alert mice. J Neurosci 24:434-441

10. Álvarez MI, Lacruz C, Toledano-Díaz A, Monleón E, Monzón M, Badiola JJ, Toledano A (2008) Calretinin-immunopositive cells and fibers in the cerebellar cortex of normal sheep. Cerebellum $7: 417-429$ 
11. Shakkottai VG, Chou CH, Oddo S, Sailer CA, Knaus HG, Gutman GA, Barish ME, LaFerla FM, Chandy KG (2004) Enhanced neuronal excitability in the absence of neurodegeneration induces cerebellar ataxia. J Clin Invest 113(4):582-590

12. Liao YJ, Safa P, Chen YR, Sobel RA, Boyden ES, Tsien RW (2008) Anti- $\mathrm{Ca}^{2+}$ channel antibody attenuates $\mathrm{Ca}^{2+}$ currents and mimics cerebellar ataxia in vivo. Proc Natl Acad Sci U S A 105(7):2705-2710

13. Pietrobon D (2005) Function and dysfunction of synaptic calcium channels: insights from mouse models. Curr Opin Neurobiol $15: 257-265$

14. Holmes SE, O'Hearn EE, McInnis MG, Gorelick-Feldman DA, Kleiderlein JJ et al (1999) Expansion of a novel CAG trinucleotide repeat in the $5^{\prime}$ region of PPP2R2B is associated with SCA12. Nat Genet 23:391-392

15. van de Warrenburg BP, Verbeek DS, Piersma SJ, Hennekam FA, Pearson PL, Knoers NV, Kremer HP, Sinke RJ (2003) Identification of a novel SCA14 mutation in a Dutch autosomal dominant cerebellar ataxia family. Neurology 61:1760-1765

16. Yabe I, Sasaki H, Chen DH, Raskind WH, Bird TD, Yamashita I, Tsuji S, Kikuchi S, Tashiro K (2003) Spinocerebellar ataxia type 14 caused by a mutation in protein kinase $\mathrm{C}$ gamma. Arch Neurol 60:1749-1751
17. Verbeek DS, Knight MA, Harmison GG, Fischbeck KH, Howell BW (2005) Protein kinase C gamma mutations in spinocerebellar ataxia 14 increase kinase activity and alter membrane targeting. Brain 128:436-442

18. Adachi N, Kobayashi T, Takahashi H, Kawasaki T, Shirai Y, Ueyama T, Matsuda T, Seki T, Sakai N, Saito N (2008) Enzymological analysis of mutant protein kinase Cgamma causing spinocerebellar ataxia type 14 and dysfunction in $\mathrm{Ca}^{2+}$ homeostasis. J Biol Chem 283(28):19854-19863

19. Walter JT, Alvina K, Womack MD, Chevez C, Khodakhah K (2006) Decreases in the precision of Purkinje cell pacemaking cause cerebellar dysfunction and ataxia. Nat Neurosci 9:389397

20. Underwood BR, Rubinsztein DC (2008) Spinocerebellar ataxias caused by polyglutamine expansions: a review of therapeutic strategies. Cerebellum 7:215-221

21. Manto M, Bastian AJ (2007) Cerebellum and the deciphering of motor coding. Cerebellum 6:3-6

22. Liao L, McClatchy DB, Park SK, Xu T, Lu B, Yates JR 3rd (2008) Quantitative analysis of brain nuclear phosphoproteins identifies developmentally regulated phosphorylation events. J Proteome Res 7(11):4743-4755 